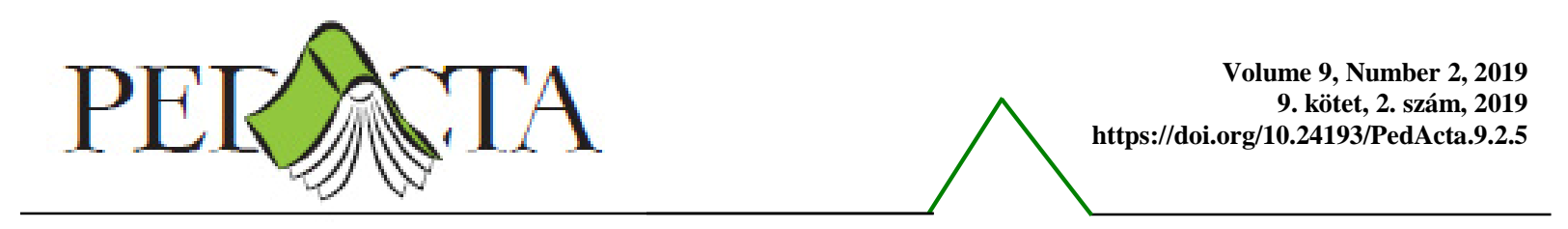

\title{
INDUCTION OF UNIVERSITY TEACHERS: PERCEPTIONS, PROBLEMS AND PERSPECTIVES
}

\author{
Kairat Gulsaule, Mandel Kinga Magdolna
}

\begin{abstract}
Taking the first steps into an academic path career or making a move to a new academic job can be complex and demanding. Induction period of a newly hired university teacher is a flexible realignment mechanism to the ever changing conditions of the higher education environment whereas purposefully acquiring the competences of instruction and research.

The study aims to analyze the induction period of newly appointed academics just right about to start their career. We seek to answer on how they define themselves, what kind of barriers they encounter, how they cope with those hardships in order to stay motivated and enrich their professional knowledge. Semi- structured one-to-one interviews with fifteen beginning novices from one of the higher education institutions in Kazakhstan demonstrate what kind of challenges they faced during their transition period.
\end{abstract}

Keywords: academic induction, professional socialization, higher education

\section{Introduction}

The quality of teaching and learning as well as reforms and modernization in higher educational institutions directly depend on the quality and competence of teachers working there (EC, 2011). Teachers are main elements in getting the success of any system of education.

Taking the first steps into an academic path career or making a move to a new academic job can be extremely complex and demanding (Staniforth and Harland, 2006), including both professional and personality development concerns. Socialization and development of an individual is delineated as a hierarchically structured function in a society. Yet, it is at the same time a closely interlaced, interpenetrating, continuously complicated social and educational system.

Personality development is determined by a complex of various living circumstances of society and each separate individual, which causes diverse and varied situations of personality development.

Profound alterations in social, economic, political, cultural and educational conditions assume a higher education teacher to have the ability to take a decision in uncontemplated and irregular situations (Clegg, 2008). With the changes taking place in universities, academics face a number of requirements which effect on their roles such as institutional research and development, enterprise and community partnership, 'hard' managerialism (Knight and Trowler, 2000) and, certainly, teaching and learning, thus leading to the emergence of multiple identities, sometimes conflicting (Lamont and Nordberg, 2014).

\section{Academic induction of newly hired university teachers}

Currently problems on academic induction are getting more and more essential and researched by specialists from different spheres. This term is being studied from various aspects and approaches. A great importance is given to school teachers, how the induction programs work and function in their case (Zeichner and Tabachnick, 1985; Varah, Theune and Parker, 1986; Kidd, Brown and Fitzallen, 2015; Blömeke et al., 2015), but there are only a few studies devoted to the induction period of young academics in higher education institutions (Billot, 2010; Fitzmaurice, 2013; Trede, Macklin and Bridges 2012). 
Trede, Macklin and Bridges (2012) carried out a systematic review on professional identity formation in the university setting and they also concluded that "there is a dearth of journal articles that comprehensively explore the development of professional identity through higher education" (Trede, Macklin and Bridges, 2012, 368).

Billot (2010) highlights that the effectiveness of academic induction in the field of higher education is under-monitored and argues that higher education institutions should give much prominence to professional socialization through adequate and supportive scaffolding of the numerous tasks and duties that new professional educators need to take on.

In general, induction period, as defined by Trethowan and Smith (1984, 1, cited in Katz and Coleman, 2001 ) is a process "which enables a newcomer to become a fully effective member of an organization as quickly and as easily as possible" with the aim to socialize, achieve competence and exposure to an institutional culture (Katz and Coleman, 2001).

In a study which set out to examine academic induction in the universities, Staniforth and Harland (2006) reported that typical formal activities for newcomers in the academic career should include institutionwide orientation programs, mentoring schemes and departmental handbooks. But apart from these supporting programs for newcomers, as the authors claim, the department itself and the head of it plays the most significant social site for adaptation period. Because heads hold a powerful position in relation to a new staff and act as 'gatekeepers in authorizing certain academic activities' (Staniforth and Harland, $2006,186)$, they are also in control of performance evaluation and tenure decisions. In the same vein, Fulton, Yoon and Lee (2005) in their study contemplated the system of induction as a network embracing supports, people and processes that are all targeted on assuring that new faculty members become effective in their professional work. Induction process, apart from being just a phase, should represent a network of relationships and supports with well-defined roles, activities and outcomes (Fulton, Yoon and Lee, 2005).

Adaptation is a process. A process is a sequential change of a number of stations of definite live situations and thoughts which leads to quality alterations and transition to different occurrences. The precise adaptation refers not only to progression or changes, but also to development which is characterized with quality, directedness, irreversibility. The vital source of development is contradictions (Pinheiro, Benneworth and Jones, 2012), thus being the main driving force of the adaptation process which will be the core of the induction period of a newly hired. These contradictions may be: well trained in theory and inefficiency in using this theoretical knowledge in practice; the content and level of preparedness to implement in teaching activities, the content and diversity of requirements to fulfill it; gained knowledge necessary to accomplish teaching goals; professional expectations and actual professional reality; social expectations and challenges and actual role in the structure of interpersonal relationships with faculty staff members; personal interests and needs to opportunities and requirements of the professional occupation. In general, as Mullins $(2005,816)$ highlighted, "induction should include attention to rules and regulations, familiarization with the culture and methods of operation of the organization, and personal training and development needs".

On the base of professional contradictions lies the discrepancy between the system of requirements specified for young specialist's professional work in higher education and the fulfillment of these requirements in the professional work in particular work conditions. In the professional work this discrepancy is noticed as shortages, failures and drawbacks. Hereby, resolving of hardships and pitfalls as well as identifying and coping with failures faced by young academics represent the core mechanism of their transition period (Martinez, 2008). Also, the research indicates that teacher turnover rates reduce when newcomers are maintained with assistance and support during their initial years of teaching (Smith and Ingersoll, 2004).

Coping with hardships and failures is a perplexed process which requires a compound of conditions and circumstances affecting influence on the positive result of it. These given circumstances refer to factors of professional adaptation. Since the induction period is contained in managing to solve the essential contradictions of this period, there appears the need to delineate the nature of this discordance, to analyze the causes and reasons of this discordance and search for effective ways to preclude them, to implement targeted ways in practice and make analysis on their effectiveness. Thus, induction period of a young 
academic can be divided into three main stages according to the above-mentioned processes: diagnostic, analytic and, practical.

Currently, higher education, hence university teachers accomplish three main pedagogical functions: teaching, developing and educational. But, irrespective to its traditional formulation, each of them is moderately expanded with new content considering the needs of the society.

Teaching function of an academician consists not only in teaching students to actual and theoretical knowledge, introducing them with modern scientific achievements in the fields of education, improving practical knowledge and skills related with studying each of the scientific disciplines, but also developing in students' needs in self-development and self-improvement, leading their creative and intellectual activities to acquire knowledge individually.

One of the substantial directions of reorganization in the pedagogical process in the field of higher education is to form and develop personalities of future specialists, improve their creative potentials as well as individual opportunities. Thereby, developing function of university teacher comes forward in this leading part. In the developing process university academics should not only create conditions for self-knowledge and self-actualization of each student, but also exploit the need for continuous selfdevelopment, the ability to make it reality.

In integral and essential part of pedagogical process remains its educational function of university teacher focused to reform and improve inner characteristics of a human being, his needs, values, relationship systems to nature, society, labor as well as to himself, as a consequence alteration of his behavior to the necessary direction.

The research shows that a teaching profession shouldn't be like 'an egg carton profession' (Lortie, 1975) where teachers are kept separately from each other and do not collaborate for the effective professional development and learning. On the contrary it should be fundamentally a collegial profession (Johnston, 2009).

Primary factors which outline the establishment of interpersonal relationships in a community, social or pedagogical, are involvement of academics in a joint research and teaching activities, improvement of psychological knowledge about students, colleagues and about him/herself, enhancement of culture of communication, enrichment of professional development, formation of emotional and motivational areas, etc. But, unfortunately, today in higher education institutions we face 'loss of collegiality' (Knight and Trowler, 2000, 6) due to the lack of time, pressure of conducting research, "the opportunity to share and discuss good practice and problems in teaching and learning is increasingly lost" (Knight and Trowler, 2000, 6).

Overall, the studies on the induction period of new university teachers highlight the need for implementing formal mentoring schemes or programs as mentoring is commonly associated with inducing as well as professional development tool for the faculty (Katz and Coleman, 2001).

\section{Methods}

To coincide with the main purpose of this survey, a qualitative method was carried out. Data was collected using semi-structured one-to-one interviews as interviews provide rich and useful information, help researchers learn about the phenomenon and give voice to silenced people (Creswell, 2012).

A basic interview guide was used. However, the conversations which were informal in nature allowed beginning academics to take the conversations in different directions given their own experiences. Anonymity and confidentiality of participated university teachers was maintained. Interviews were audio- taped, but there were some teachers who insisted on not being recorded. Their desires were respected and during their interviews just notes were taken. Further, interviews were transcribed verbatim to facilitate consequent data analysis.

Semi- structured one-to-one interviews, lasting approximately 30-40 minutes, began with the questions to evolve young academics' interest in science, and these questions included general questions that were 
focused on beginning academics' background education, professional and personal experiences in their induction period.

\section{Participants and the context}

For the participants of the interviews it was planned to involve junior staff members with maximum of five years of work experience in the field of higher education. After five years of working at the university teachers apply for the application to be promoted to get 'a senior teacher' status in Kazakhstan. Some teachers can get this status after three years of work experience if they meet the requirements of the application. Bearing this in mind the invitation letters were disseminated to six faculty junior members of Sh. Ualikhanov Kokshetau State University.

Sh. Ualikhanov Kokshetau State University is one of the leading universities in the Northern part of Kazakhstan which trains specialists on different directions among which Education, Human and Social Sciences, Arts, Business, Natural Sciences, Agricultural Sciences, Technical Sciences and Technologies, etc. The languages of instruction are Kazakh and Russian. According to the official webpage of the university there are more than 11,000 students, with 271 Master degree students and 33 $\mathrm{PhD}$ students. As to the teaching staff, it comprises 410 university academics: 20 professors, $13 \mathrm{PhDs}$, 92 associate professors and 214 teachers with Master's degree. 35 university teachers hold the State honor "Best Higher Education Teacher".

Since the implementation of the State Program on "Trinity of Languages" some specialties are instructed in English and teachers are being trained to teach in English. The program aims to develop teaching and learning of three languages: Kazakh as the state language, Russian as the second state language and language of interethnic communication, and English as the international language.

Its purpose is to strengthen the country's capacity. A polylingual person will always be in demand in any society. That's why school and university subjects are planned to teach in three languages (Kazakh, Russian and English).

Junior staff members who volunteered to participate in this survey, aged from 26 to 32 years old, have different length of work experience in the higher education institution. Only one interviewee was a male, the rest were female which corresponds to the usual share of gender all over the world in higher education (see Table 1):

Table 1. Information about the participants

\begin{tabular}{|l|l|l|l|l|l|l|}
\hline No. & Interviewee & Age & Gender & Nationality & $\begin{array}{c}\text { Work } \\
\text { experiencel } \\
\text { year }\end{array}$ & $\begin{array}{c}\text { Language of } \\
\text { communication } \\
\text { in the } \\
\text { interview }\end{array}$ \\
\hline 1 & Interviewee1 & 29 & female & Kazakh & 1 & English \\
\hline 2 & Interviewee2 & 26 & female & Kazakh & 2 & English \\
\hline 3 & Interviewee3 & 32 & female & Kazakh & 5 & English \\
\hline 4 & Interviewee4 & 29 & female & Kazakh & 3 & English \\
\hline 5 & Interviewee5 & 29 & female & Kazakh & 2 & Russian \\
\hline 6 & Interviewee6 & 32 & female & Kazakh & 3 & Kazakh \\
\hline 7 & Interviewee7 & 26 & female & Kazakh & 2 & English \\
\hline 8 & Interviewee8 & 26 & female & Kazakh & 1 & English \\
\hline 9 & Interviewee9 & 31 & female & Kazakh & 5 & Kazakh \\
\hline 10 & Interviewee10 & 31 & female & Kazakh & 3 & Kazakh \\
\hline 11 & Interviewee11 & 28 & male & Kazakh & 2 & Kazakh \\
\hline
\end{tabular}




\begin{tabular}{|l|l|l|l|l|l|l|}
\hline 12 & Interviewee12 & 32 & female & Kazakh & 2 & Kazakh \\
\hline 13 & Interviewee13 & 27 & female & Kazakh & 1 & Kazakh \\
\hline 14 & Interviewee14 & 30 & female & Kazakh & 2 & Kazakh \\
\hline 15 & Interviewee15 & 29 & female & Kazakh & 2 & Kazakh \\
\hline
\end{tabular}

\section{Findings and discussions}

The analysis of the interview transcripts allowed us to divide the challenges faced by the beginning academics into the following three general groups (Figure 1):

1) Challenges in organization and administration;

2) Challenges in teaching (includes the acceptance of the role of a new university teacher, affects of new educational reforms in Kazakhstan, impacts of new working environment);

3) Challenges in research.

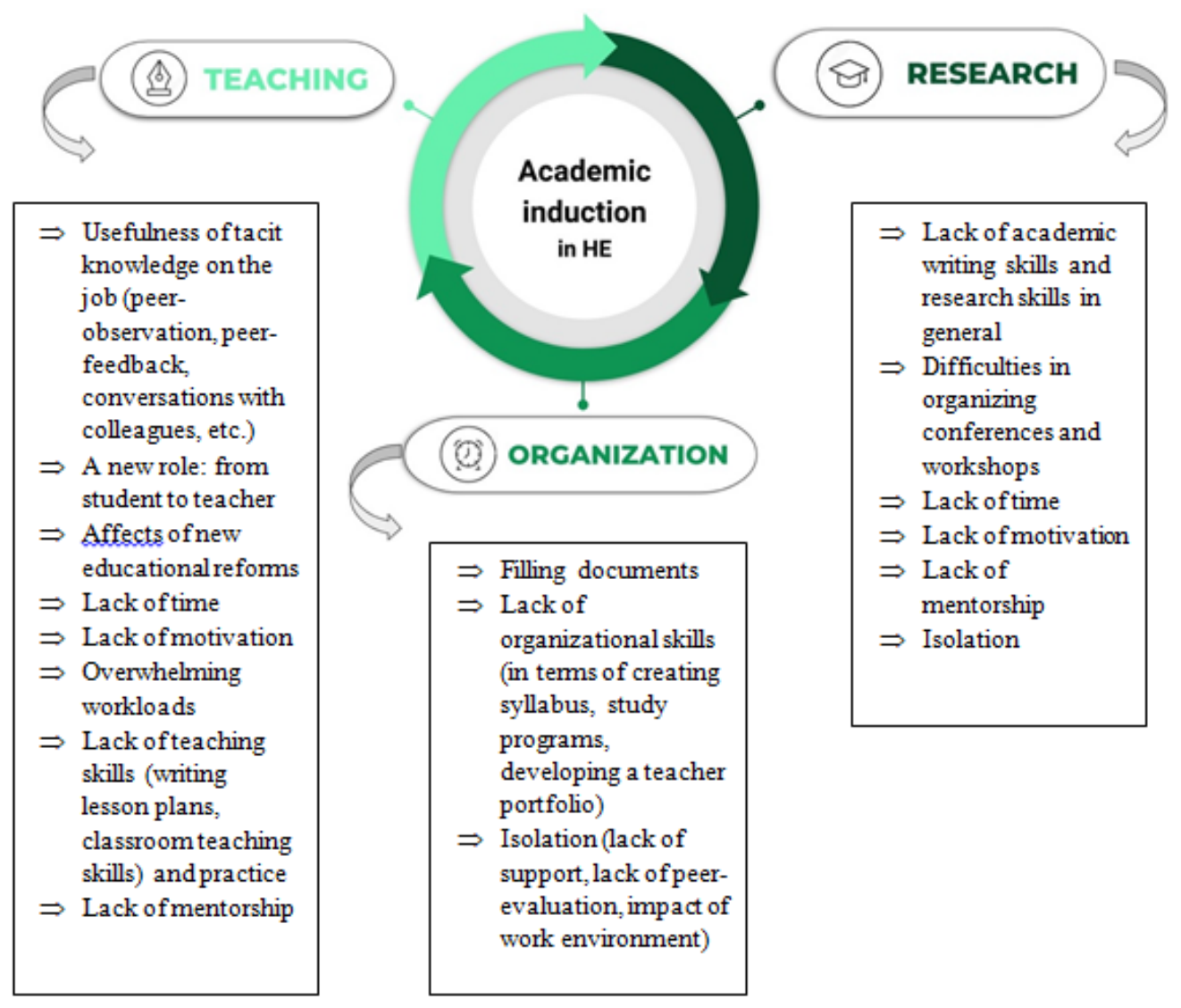

Figure 1 . The main challenges faced by young university teachers in Sh. Ualikhanov, Koshetau State University, Kazakhstan

If we turn back to the literature overview on academic mentoring, most of the authors are in agreement that mentoring is 'a form of personal and professional partnership' (Arnold, 2006, 117) in which a mentor on the voluntary base gives time to support and encourage his or her mentee. 'This is typically developed at a time of transition in the mentee's life, and lasts for a significant and sustained period of time' (Meier, 2008, 2). Traditionally, these mentorship relationships are constructed on one-to-one relationships. Here, the question is raised on whether a group of experienced teachers can mentor a newcomer or a group of newcomers.

As the results of the survey show informal mentoring is organized in a form of group mentoring: an experienced senior teacher educator of the faculty 'takes care' of 3 or 4 newly hired juniors. The basis 
of these relationships is related to transfer of mentor's knowledge and sharing with their rich teaching experience. This form of group mentoring is practiced in the department of English Language and Teaching Methods. The departments of Foreign Languages, Kazakh language and Literature, and Chemistry seem to have an individual informal mentor. New entrants just reach out their mentors when they feel some kind of lostness or frustration and ask for help with the planning of lessons or syllabus. If new entrants feel shy or unconfident, they do not ask for help and support. This, in turn, results the feeling of isolation in the fields of teaching and research (as seen from Figure 1).

Overall, as interviews with newly appointed faculty members show, in practice when young university teachers are provided with appropriate support and assistance, teachers turnover rates and 'shocking by entering the profession' decrease (Smith and Ingersoll, 2004). As the research Knight and Trowler (2000) demonstrates, in Kazakhstan the situation turned out to be the same: due to the lack of time and huge workloads academicians do not have extra time to collaborate to engage in joint research projects or to form and develop networks of teachers (Fulton, Yoon and Lee, 2005).

\subsection{A new role - new responsibilities (organization and administration)}

The requirements of research and teaching in the higher education requires possession of high professional knowledge and skills, mastering of modern pedagogical methods and techniques as well as acknowledged personal responsibility for the quality of education, development of creative and erudite professionals responsible for well-being of students and society in general. Junior academics entering their academic career, first and foremost, encounter the problems on accepting their new role as a university teacher. First of all, this is seen in transitioning from a student status into a teacher status:

"When I started to work at the university, just after graduating from my university, so it was a little bit difficult. Because I was no longer a student, I was a teacher and that was a new role for me and new responsibilities confused me a little bit. The main difficulty was to adapt to new teacher's role, to assess students and of course to deal with paper work like creating a syllabus, checking students' formative and summative works" (Interviewee 7, 26, female, 2 years of experience).

Despite the listed obstacles the interviewee is very positive about her induction period. Thinking back to this period she remembered how her colleagues and a friendly atmosphere helped her to overcome that tension which demonstrates how the working environment and supportive and guiding team members can positively effect on a young specialist.

One of the most mentioned difficulties which the novice teachers challenged in their new working place was dealing with the documentation, specifically filling administrative documents in the right way and developing subject syllabuses. It should be mentioned that the syllabuses are prepared according to the language of instruction of the subject. This means that faculty teachers prepare the syllabuses for their taught subjects in three languages: Kazakh, Russian or English. This, in turn, comprises another obstacles dealing with the documentation:

"Though I have already had one-year experience at school being a teacher at the university, turned out to be a bit different. In terms of documentation and working conditions. Though the first week I was overloaded, I had to process a lot of information in my mind, settling to a new environment" (Interviewee 4, 29, female, 3 years of experience).

In the same vein was another participant who stated, "when I started working, the first thing I found difficult was dealing with the documentations. Then it was how to create the syllabus, how the portfolio should be developed, what is expected from students" (Interviewee 11, 28, male, 2 years of experience).

Among pitfalls in the adaption to the new working place were failures in accurately planning of time management, logically developing units and sequential steps of lessons, difficulties in explaining new material to students, working with students:

"I always struggle with time management in my classes" (Interviewee 4, 29, female, 3 years of experience).

"In the first week I had some difficulties with students. I was a supervisor of some groups and I didn't know what kind of responsibilities I should do, how to meet students, what kind of information I should provide and take from them" (Interviewee 5, 29, female, 2 years of experience). 
"As a new staff member, though you know everything theoretically well, in reality I felt a strong feeling of not having a practical knowledge. This was seen in works like lesson planning, filling the papers, working with students' paper work and many other documents" (Interviewee 14, 30, female, 2 years of experience).

Adaptation of a newcomer specialist is a mechanism of a flexible realignment to the changing conditions of the environment as well as purposefully acquiring the norms of collective professional communication, organizational knowledge and keeping the organizational traditions. Lack of peerevaluation and motivation of each other (of teachers at the faculty) was found as one of the influential factors. However, not all novices were challenged by this. Thus, for instance, Interviewee 7 was lucky enough in her transition period as she graduated and started to work at the same university. This happened to most of the respondents who found to work with their previous professors as their colleagues easy and with less stress whereas those who were quite new in that place felt to be isolated:

"It seemed to me that everybody in our department worked by their own. Everybody seemed working alone by themselves. But as time passed I got used to the environment" (Interviewee 11, 28, male, 2 years of experience).

Here, newly hired worker's motivation plays a crucial and significant role which can positively affect his/her colleagues as well as advantageously impact on the organization, in general. This was highly emphasized by two of the respondents:

"If you don't ask for help and deal with your difficulties only by yourself, then it depends on your motivation and strength. But if you ask your colleague, he/she will definitely help you, will show, how to work. So, everything is on your hand, it's only up to you" (Interviewee 11, 28, male, 2 years of experience).

The context of teaching, mainly social environment, appeared to be essential in the process of teaching adults and teaching students. As it's known, Knowles' third assumption is related with the role of the adult learners' experiences (Knowles et al., 2014). When working with adult students, some junior teachers were not confident in developing lesson plans considering student's interests and experiences. But, in general, transition period of all respondents seems to pass easily and without less stress due to the positive atmosphere in the workplace, due to their colleagues' support, advice, assistance, guidance and help: 5 respondents felt hardships in their early career steps. The rest were positive about their induction period and early career path. We suppose this is connected with the reason that those ten junior teachers are the graduates of the same department where they currently work. It was easier for them to cope with the pitfalls since their colleagues were their previous teachers and professors. Still, the challenges mentioned above caused the same stress to all of them.

\subsection{Teaching in higher education}

In general goals of teaching and educating future experts' professionalism of the novice teacher, who has just graduated the university, requires deep learning, reflection and careful analysis of the process of his/her forming process as a professional. Professionalism is a major factor of composed qualifications.

The interviewees emphasized on the usage and significance of the tacit knowledge for the enhancement of their professional knowledge and teaching practice. Daily conversations with peer- colleagues, personal wisdoms from senior colleagues, learning by being told and learning by observation in the new organizations seems to facilitate new comer's transition period fruitful and effective: “...my mentor always shares his rich experiences, shows how to do and how to work, I find this more impactful and practical. I think this kind of knowledge cannot be found in books or in any other theoretical publications" (Interviewee 9, 31, female, 5 years of experience).

Junior academics acknowledge the fact that even though you graduate with well-established theoretical base, in practice that base seems to be like the emerged part of an iceberg and the rest tremendous part of it elaborated through the tacit knowledge, through observing other teachers, receiving peer feedback, cultivating collegial relationships, and participating in lifelong learning experiences (Stronge, 2002). 
As Susanne Garvis (2012) noted in her article, for a young new teacher educator, it's very hard to start working since "no one gives you a manual on what to do. You teach in isolation" (Garvis, 2012, 298) and it's often "filled with tension" (Garvis, 2012, 300). To avoid isolation, the respondents indicated on the importance of having a formal mentor:

"The first difficulty was absence of mentor and teaching different subjects in different courses" (Interviewee 12, 32, female, 2 years of experience).

"When I started working, of course, I faced some challenges. For a teacher who has just graduated, who has no experience, I think, it's important to appoint a mentor who will support, guide to a new direction and raise his mentee's confidence and self-esteem. So, it's important to have a person beside you to adapt to a new working place" (Interviewee 10, 31 female, 3 years of experience).

\subsection{Research in higher education}

Research is one of the fundamental functions of higher education institutions. Publication and innovational performances of pedagogical staff, their involvement in the research, actively or passively, come out as a kind of indicator, hence, characterizing the actual position of the university and its staff in general.

Therefore, for the newly appointed academician, who has already many difficulties in teaching practice and administrative things, the engagement in the research seems to get them in a tangle:

"Since I worked at the university, research also became one part of your job. Writing research articles, participating in conferences, workshops, organizing workshops for teachers, organizing an open lesson as a young university teacher, these all made some difficulties because of the absence of scientific knowledge and background. However, there are councils for young scientists within the university. Members of it are young university teachers from each department. Above mentioned research projects, the ways of organization of conferences and seminars, how to participate, how to write articles, all is discussed there. Students are also involved to this council, so from this now their scientific knowledge is being developed" (Interviewee 11, 28, male, 2 years of experience).

The interview participants explained the system of conducting research in their university. At the beginning of each academic year, new lecturers fill in an individual plan where he/she plans what is going to be done in terms of research: to publish at least three articles, to participate in different kinds of conferences, workshops and seminars, to organize one workshop or seminar at the faculty for the staff, to be a supervisor, etc. But the question of the 'teaching- research nexus' remains under the discussion because the respondents couldn't connect the idea if university teachers' research can inform their teaching or not. In the initial phase of their career newly hired teachers seem to care more about their teaching rather than research and it's not surprising with the limited number of hours in their working day.

Here, again support and assistance of a mentor or of colleagues were of great help:

"They [mentors] enriched my knowledge on how to conduct the research, how to identify relevant focuses, they also told about possible drawbacks. Of course, in practice all of these kinds of knowledge are more essential than just reading from papers" (Interviewee 10, 31, female, 3 years of experience).

Definitely, for a new academic to have all these multiple roles and to find a balance between them are difficult and hard as you are all the time overloaded with these tasks. What is more, the lack of time is found to be crucial at the very early stage of novices. One teacher mentioned, "A job is new to you and you need to learn, how to do it, there is a lot of things that you do over your job, you need to be really organized. So, the lack of time is the main difficulty" (Interviewee 1, female, 1 year of experience).

\section{Concluding remarks}

The research indicates that work in higher education is challenging and stressful for new entrants (Boyd, Harris and Murray, 2011) which are seen in our study in uncertainty about specific nature of their new professional roles, difficulty in managing with the pedagogical skills specifically designed for adult learners and concerns about the adequacy of the professional and academic knowledge bases necessary for their higher education work. 
One of the key challenges occurred in tertiary education for novices is that it's underpinned by teaching and research. To support the research development of new university teachers the mission of departments is therefore to provide effective support through mentoring and collaborative projects. Since newcomers do not have a real full picture about their profession, from their first steps into the profession they shouldn't be overwhelmed with paper work. Informal mentoring supports from their peer or senior colleagues should be realized in a formal mentoring program including additional learning experiences. In such way newly hired members will know 'what are expected' from them, starting from the documents and ending with students' works and papers. Young teachers of this survey mentioned about the existence of peer lesson observations which are recorded only in the formal papers. But if the departments will use this as an opportunity for sharing experience and knowledge, receiving useful and meaningful feedback, then junior teachers will be motivated and inspired to strive forward and improve their teaching skills and knowledge.

Undoubtedly, it's not possible to make conclusions from this research. However, through such kind of small studies we can identify what kind of challenges face young teacher educators, how these barriers can be solved, what factors influence on their work.

Another point is that the question of teacher's professional identity is an emerging field in teacher education of the last decade (Beijaard, Meijer and Verloop, 2004). Together with examining teacher identity, the attention should be given to their work itself. This study is not devoted purely to the issues of teacher identity. However, from entering the career, from the failures and successes develops his or her identity formation.

As seen from the participants' interviews, teacher's work in higher education is becoming more complex and challenging. Because of their numerous kinds of tasks (apart from teaching, they need to work as well in the field of research, administration and many other obligations) the issue of the quality of teaching is also under question.

\section{Bibliography}

Arnold, E. (2006): Assessing the quality of mentoring: sinking or learning to swim? ELT journal, 60(2), 117-124.

Beijaard, D., Meijer, P. C., Verloop, N. (2004): Reconsidering research on teachers' professional identity. Teaching and Teacher Education, 20(2), 107-128.

Billot, J. (2010): The imagined and the real: Identifying the tensions for academic identity. Higher Education Research \& Development, 29 (6), 709-721.

Blömeke, S., Hoth, J., Döhrmann, M., Busse, A., Kaiser, G., König, J. (2015): Teacher change during induction: Development of beginning primary teachers' knowledge, beliefs and performance. International Journal of Science and Mathematics Education, 13(2), 287-308.

Boyd, P., Harris, K., Murray, J. (2011): Becoming a teacher educator: guidelines for induction.

Clegg, S. (2008): Academic identities under threat? British Educational Research Journal, 34(3), 329345 .

Creasy, K. L. (2015): Defining professionalism in teacher education programs. Online Submission, 2(2), 23-25.

Creswell, J. W. (2012): Educational research: Planning, conducting, and evaluating quantitative and qualitative data.

European Commission (2011): Communication from the Commission to the European Parliament, the Council, the European Economic and Social Committee and the Committee of the Regions: Supporting growth and jobs - an agenda for the modernisation of Europe's higher education systems. COM(2011) 567 final. Brussels.

Fitzmaurice, M. (2013): Constructing professional identity as a new academic: A moral endeavour. Studies in Higher Education, 38(4), 613-622. 
Fulton, K., Yoon, I., Lee, C. (2005): Induction into learning communities. National Commission on Teaching and America's Future.

Garvis, S. (2012): A Self-study in teacher education: Learning to teach in higher education after teaching the arts to young children. Online Submission.

Johnston, B. (2009): Collaborative teacher development. In Burns A., Richards, J. C. (Eds.). Guide to Second Language Teacher Education. Cambridge: CUP, 241 - 249.

Katz, E., Coleman, M. (2001): Induction and mentoring of beginning researchers at academic colleges of education in Israel. Mentoring and Tutoring, 9(3), 223-239.

Kidd, L., Brown, N., Fitzallen, N. (2015): Beginning teachers' perception of their induction into the teaching profession. Australian Journal of Teacher Education, 40(3).

Knight, P. T., Trowler, P. R. (2000): Department-level cultures and the improvement of learning and teaching. Studies in Higher Education, 25(1), 69-83.

Knowles, M. S., Holton III, E. F., Swanson, R. A. (2014): The adult learner: The definitive classic in adult education and human resource development (8th ed.). RoutledgeFalmer: Taylor \& Francis Group.

Lamont, C., Nordberg, D. (2014): Becoming or unbecoming: Contested academic identities.

Lortie, D. (1975): School teacher: A sociological study. Chicago, IL: University of Chicago Press.

Martinez, K. (2008): Academic induction for teacher educators. Asia-Pacific Journal of Teacher Education, 36(1), 35-51.

Meier, R. (2008): Youth mentoring: A good thing? Surrey, Centre for Policy Studies.

Mullins, L.J. (2005): Management and organisation behaviour (7th edn. ed.). Harlow: Pearson Education.

Pinheiro, R., Benneworth, P., Jones, G. A. (Eds.). (2012): Universities and regional development: A critical assessment of tensions and contradictions. Routledge.

Smith, T. M., Ingersoll, R. M. (2004): What are the effects of induction and mentoring on beginning teacher turnover? Educational Evaluation and Policy Analysis, 26(3), 681-714.

Staniforth, D., Harland, T. (2006): Contrasting views of induction: The experiences of new academic staff and their heads of department. Active Learning in Higher Education, 7(2), 185-196.

Stronge, J. (2002): Qualities of effective teachers. Alexandria, VA: Association for Supervision and Curriculum Development.

Tichenor, M. S., Tichenor, J. M. (2005): Understanding teachers' perspectives on professionalism. Professional Educator, 27, 89-95.

Trede, F., Macklin, R., Bridges, D. (2012): Professional identity development: a review of the higher education literature. Studies in Higher Education, 37(3), 365-384.

Varah, L. J., Theune, W. S., Parker, L. (1986): Beginning teachers: Sink or swim? Journal of Teacher Education, 37(1), 30-34.

Zeichner, K. M., Tabachnick, B. R. (1985): The development of teacher perspectives: Social strategies and institutional control in the socialization of beginning teachers. Journal of Education for Teaching, 11(1), 1-25.

\section{Authors}

Kairat Gulsaule, Eötvös Loránd University, Budapest (Hungary). E-mail: gulsaule@ caesar.elte.hu,

Mandel Kinga Magdolna, Eötvös Loránd University, Budapest (Hungary). E-mail: mandel.kinga@ppk.elte.hu. 